\title{
CIBERBULLYING EN ESTUDIANTES UNIVERSITARIOS
}

\author{
Alex Javier López González ${ }^{1}$ \\ Laura López Díaz ${ }^{2}$ \\ Nelson Javier Cetz Canché ${ }^{3}$ \\ Rubén Jerónimo Yedra ${ }^{4}$
}

\begin{abstract}
Bullying is a behavior pattern where an individual is chosen as the target of a systematic aggression, by one or more people, becoming the expression of the same problem electronic harassment or cyberbullying, highlighting processes that involve aspects of virtual violence, provoked for the misuse of technologies. In the present work of investigation, the main problems of electronic harassment with which the students of the Juárez Autonomous University of Tabasco are described are described. A questionnaire was applied to obtain results such as the electronic media where more harassment is carried out, people involved in this and those who address it when it happens. Also, some measures to detect bullying in children are mentioned, emphasizing how it is possible to avoid it.
\end{abstract} Keywords: Cyberbullying, University students, TIC, Sexting.

\section{Introducción}

En la actualidad las Tecnologías de la Información y Comunicación (TIC), en particular el Internet es un gran sistema creado por los seres humanos, que implica la conexión de millones de dispositivos que conforman redes descentralizadas para formar una gran red global. En dicha red se manifiestan una serie de actividades que provocan ciertos factores negativos dentro de las mismas, como son los robos virtuales, secuestros, etc., mejor conocidos como cibercrimenes. Al igual que se practica la nueva faceta del acoso escolar virtual o Ciberbullying, que lo sufren tanto hombres como mujeres.

Por lo anterior, y ante tantas situaciones ilegales en el Internet, en el Estado de Tabasco se creó la Unidad 
Especializada Centrada en Bullying, a raíz de un convenio firmado el 15 de febrero de 2011 por la Procuraduría General de Justicia del Distrito Federal (PGJDF) y la Secretaría de Educación del Distrito Federal. Aproximadamente 20 millones de los internautas en México tienen menos de 18 años y pueden ser víctimas de ciberbullying. Asimismo, describe que las mujeres tienden a sufrir de violación de intimidad, es decir, cuando un estudiante embauca a otro para realizar actos de intimidad y luego los difunde de forma masiva por el celular o algún otro medio. Cabe destacar que la violación de intimidad es diferente al sexting, acto que se define como el envío entre iguales de mensajes con contenido sexual por medio de dispositivos móviles. El sexting no es en sí mismo un acto de ciberbullying, sin embargo, es una puerta de entrada para que el contenido enviado sea filtrado o compartido, lo que entonces se convertiría en un acto de violación de intimidad (Gob.mx, s.f.)

Corsi y Peyrú (2003), precisan que "es un tipo de violencia que ha llamado la atención de diversos investigadores en el país y en el mundo y
116 que existen resultados de investigación que dan cuenta de su presencia en las distintas aulas de los diversos niveles educativos. Es una agresión intencional, por parte de un grupo o un individuo, que utiliza diversas formas electrónicas de manera repetida, a una víctima que no puede defenderse fácilmente por sí misma".

Otro concepto de sexting, es que consiste en "mandar imágenes propias, fotografías y vídeos íntimos, o con contenido sexual, que son tomadas y grabadas por los protagonistas de las imágenes o, con su consentimiento, por terceras personas $\mathrm{y}$ posteriormente difundidas de manera no consentida. El origen se encuentra por tanto en una acción voluntaria y confiada por parte de quien toma sus imágenes y las envía, pues sus destinatarios suelen ser personas de su confianza, como la pareja o los amigos íntimos" (Agencia española de Protección de Datos, 2016, p. 4).

Las características que distinguen la práctica del sexting, son las siguientes:

a) Para que exista debe haber siempre una voluntariedad inicial. Por 
norma general estos contenidos son generados por los protagonistas de los mismos o con su consentimiento. No es necesaria coacción, ni en muchos casos sugestión, ya que son contenidos que alguien crea normalmente como regalos para su pareja o como una herramienta de flirteo. Es decir, generalmente el propio protagonista es el productor de los contenidos, y el responsable del primer paso en su difusión;

b) Alcance de dispositivos electrónicos. Para la existencia y difusión del sexting, es necesaria la utilización de dispositivos tecnológicos, que al facilitar su envío a otras personas también hace incontrolables su uso y redifusión a partir de ese momento;

c) Lo sexual frente a lo atrevido. En una situación de sexting, el protagonista de las imágenes posa en situación erótica o sexual. Quedando fuera del sexting, las fotografías que simplemente resultan atrevidas o sugerentes, pero no tienen un contenido sexual explícito" (Instituto Nacional de Tecnologías de la Comunicación mexicano, 2011, p.6).
De lo anterior se precisa que el Ciberbullying es un tipo de violencia el cual puede darse de manera directa o indirecta como el sexting, pero que causa daños psicológicos, sociales, familiares entre otros, a los estudiantes adolescentes y jóvenes universitarios que lo practican, $\mathrm{y}$ este se manifiesta como parte de un comportamiento agresivo intencional $\mathrm{y}$ dañino, dirigido a hombres y mujeres, es constante su presencia, y su duración puede variar de una semana e inclusive meses, se diferencia por "un abuso de poder.

Este trabajo, es resultado de una investigación desarrollada de manera particular, donde se analiza el fenómeno del Ciberbullying y cómo impacta a los estudiantes Universitarios, seleccionando como muestra para la investigación a 50 estudiantes de la Universidad Juárez Autónoma de Tabasco, adscritos a la División Académica de Ciencias Económico Administrativas (DACEA). El tipo de estudio es cuantitativodescriptivo a través de la aplicación de un cuestionario en la plataforma Google formulario. 


\section{Definición del acoso escolar y acoso} cibernético

El acoso escolar se define como la conducta agresiva y deliberada que implica un desequilibrio de poder o de fuerza y se da por motivos de raza, religión, por su aspecto, su forma de hablar, etc.

Según Chaux (2012) citado por Enríquez y Garzón (2015) determinan que uno de cada cinco estudiantes sufre el acoso escolar, manifestando recibir agresión física o verbal de parte de algún compañero, lo que en instituciones gubernamentales dicha agresión se da de manera personal y de frente al estudiante, mientras que, en las instituciones privadas, dicha situación de agresión se manifiesta dicho acoso de manera virtual o ciberbullying. Dentro de las situaciones entre jóvenes se especifica que los casos esporádicos de juego pesado, desinterés académico, conducta antisocial y los conflictos o peleas entre desconocidos no son considerados agresiones de acoso como tal. También dentro del acoso escolar se identifica que los casos de agresión se determinan por la superioridad física, psicológica o social
118

de una persona por sobre otra que tiene dificultad para defenderse, se siente atemorizada u oprimida (Enríquez y Garzón, 2015).

El acoso electrónico o ciberbullying es cuando el estudiante es atormentado, acosado, amenazado, humillado, avergonzado o abusado por otras personas desde internet haciendo difícil su identificación por el anonimato que permiten las relaciones virtuales.

El ciberbullying no es algo que ocurra una sola vez y además se presenta de distintas formas, desde insultos, discriminación o burla sobre características físicas, forma de vestir, gustos, hacer pública información o fotografías que avergüenzan a la víctima, robo de identidad y suplantación, hasta amenazas de daño físico y otros cargos que pueden ser tipificados como delincuencia juvenil.

Es imprescindible determinar que, aunque sea virtual, las características que maneja son las mismas del acoso tradicional, identificando la conducta agresiva, la manifestación del desequilibrio de poder entre víctima y 
agresor y la sistematización en la agresión.

\section{Ciberbullying en estudiantes universitarios}

En el siglo XIX, la Revolución Industrial marcó el devenir del hombre entendido como entidad social y cultural. La llegada de la era digital y, con ella, las nuevas tecnologías, ha generado un crecimiento tecnológico sin precedentes, motivando que en determinados ámbitos se hable de Segunda Revolución Industrial. Esta era tecnológica no sólo ha favorecido una mejora en la calidad de los servicios, sino un aumento espectacular en la diversidad de los mismos. Así, la implementación de estas nuevas tecnologías se está manifestando sobre lo que se ha llamado sociedad industrial, dando lugar a lo que actualmente conocemos como sociedad de la información o del conocimiento (Franco, 2005).

La sociedad de la información y el conocimiento en la que se hoy se encuentra se caracteriza por la generación de riqueza, no sólo a partir de bienes y servicios, sino también por una constante producción, gestión, almacenamiento, procesamiento y consumo de todo tipo de información, donde los usuarios más frecuentes de la tecnología digital y las redes sociales son estudiantes universitarios, ya que la educación, no permanece ajena a estos cambios tecnológicos; de hecho, el e-learning (teleformación, educación virtual, cursos on line, enseñanza flexible, educación web, docencia en línea, entre otros) es una modalidad de enseñanza-aprendizaje que consiste en el diseño, puesta en práctica y evaluación de un curso o plan formativo desarrollado a través de redes de ordenadores y puede definirse como educación o formación ofrecida a individuos empleando recursos informáticos y telecomunicaciones (Salinas, J. 2004).

Por lo anterior los estudiantes universitarios en su mayoría pasan más tiempo con una computadora con conexión a internet, para realizar tareas, actividades, participar en blogs, foros virtuales, revisar su correo electrónico y lo más recurrente, estar en redes sociales, lo que propicia mayor interacción con sus amigos y personas ajenas a estos, pero 
¿estarán los estudiantes universitarios a salvo del Ciberbullying?, tal vez se pensara que por su madurez y experiencia se mantendrán a salvo, de este tipo de violencia, pero de acuerdo con un nuevo estudio de la Universidad de Wisconsin. Después de encuestar a 265 mujeres inscritas en cuatro universidades, los investigadores encontraron que las mujeres de edad universitaria eran igual de susceptibles a sufrir los efectos negativos del acoso por internet que los jóvenes adolescentes.

Dicho estudio encontró que las jóvenes universitarias que reportaron ser acosadas por internet eran tres veces más propensas a cumplir con los criterios para definir la depresión clínica. Además, si el acoso cibernético está conectado con insinuaciones sexuales no deseadas, las probabilidades de depresión se duplicaban en un aumento de seis veces; las probabilidades de depresión a consecuencia de insinuaciones sexuales no deseadas o de una relación romántica fueron sorprendentes. Estas no son acciones inocuas. Son acciones que verdaderamente pueden desencadenar una depresión y pueden llegar a dañar a las
120

personas involucradas, una encuesta de 2014 sobre el acoso en línea del Pew Research Center, encontró que $26 \%$ de las mujeres de 18 a 24 año mencionan ser acechadas en línea, mientras que el $25 \%$ menciona haber sido el objeto de acoso sexual en línea. En ese contexto el cyberbullying, se ha teorizado en insinuaciones sexuales indeseadas en verdad empieza a verse como si tuviera que estar en el espectro de la violencia sexual y no en el del bullying.

El estudio también encontró que las chicas también son más propensas a tener un problema con el consumo de alcohol, en cuanto al problema del abuso del alcohol, son los bullies quienes más sufren, no las víctimas. El estudio no se enfocó en otros problemas de salud mental como los pensamientos suicidas. Esos casos son tan extremos y tan horribles. Pero al mismo tiempo lo que se escucha de estas mujeres en estos estudios es que esto es algo que pasa todo el tiempo a muchos de nosotros $y$ queremos saber qué otras cosas pueden suceder, ¿Si no nos suicidamos, corremos el riesgo de algo más?, ¿Hay otra cosa mala que me puede pasar a mí, como 
víctima, o algo malo pasa al bully que me ha estado molestando?

Las jóvenes que sufren el acoso por internet son alentadas a buscar ayuda y visitar las clínicas de sus universidades para hablar de su experiencia, sus sentimientos crecientes de depresión o su abuso de sustancias. Existen impactos a la salud potenciales. Esto debería estar en la arena de la salud pública y las jóvenes no deberían sentir que no pueden ir a una clínica y hablar de sus sentimientos. (Sandee, 2015).

Derivado del estudio presentado se puede decir que los casos de cyberbullying se contextualizan en el acoso sexual hacia victimas mujeres convirtiéndose en uno de los ataques con mayor impacto en las personas que lo sufren.

\section{Formas de practicar ciberbullying}

Pero no solo el acoso es la única forma de practicar Ciberbullying, hay formas muy variadas y sólo se encuentran limitadas por la habilidad tecnológica y la imaginación de los menores acosadores. Algunos ejemplos concretos podrían ser los siguientes (Flores 2008):
1. Colgar en Internet una imagen comprometida (real o efectuada mediante fotomontajes), datos delicados, cosas que pueden perjudicar o avergonzar a la víctima y darlo a conocer en su entorno de relaciones.

2. Dar de alta, con foto incluida, a la víctima en una web donde se trata de votar a la persona más fea, a la menos inteligente, y cargarle de "puntos" o "votos" para que aparezca en los primeros lugares.

3. Crear un perfil o espacio falso en nombre de la víctima, donde se escriban a modo de confesiones en primera persona determinados acontecimientos personales, demandas explícitas de contactos sexuales, etcétera.

4. Dejar comentarios ofensivos en foros o participar agresivamente en chats haciéndose pasar por la víctima de manera que las reacciones vayan posteriormente dirigidas a quien ha sufrido la usurpación de personalidad.

5. Dar de alta la dirección de correo electrónico en determinados sitios para que luego sea víctima de spam, de contactos con desconocidos. 
6. Usurpar su clave de correo electrónico para, además de cambiarla de forma que su legítimo propietario no lo pueda consultar, leer los mensajes que le llegan a su buzón violando su intimidad.

7. Provocar a la víctima en servicios web que cuentan con una persona responsable de vigilar o moderar lo que allí pasa (chats, juegos online, comunidades virtuales) para conseguir una reacción violenta que, una vez denunciada o evidenciada, suponga la exclusión de quien realmente venía siendo la víctima.

8. Hacer circular rumores en los cuales a la víctima se le suponga un comportamiento reprochable, ofensivo o desleal, de forma que sean otros quienes, sin poner en duda lo que leen, ejerzan sus propias formas de represalia o acoso.

9. Enviar mensajes amenazantes por e-mail o SMS, perseguir y acechar a la víctima en los lugares de Internet en los que se relaciona de manera habitual provocándole una sensación de completo agobio.

Recientemente, Kowalski, et al. (2010) han definido el Ciberbullyng en sentido amplio, que incluye el uso de correos electrónicos, mensajerías instantáneas, mensajes de texto e imágenes digitales enviadas a través de teléfonos móviles, páginas web, bitácoras web (blogs), salas de chat o coloquios online, y demás tecnologías asociadas a la comunicación digital.

Entre las modalidades de comunicación elegidas para la práctica del Ciberbullying, Kowalski et al. (2010), señalan entre otras: mensajería instantánea (IMs), correo electrónico (email), mensajes de texto a través de móviles (SMS), redes sociales online, chats, blogs, páginas webs, tablones de encuentros sociales, juegos por Internet, etc. Además, identifican 8 tipos de acoso cibernético diferentes:

1. Insultos electrónicos: intercambio breve y acalorado entre dos o más personas, que tiene lugar a través de alguna de las nuevas tecnologías. Intercambio de e-mails privados o intercambio en contextos públicos como chat. Intercambio mutuo de insultos entre varias personas implicadas.

2. Hostigamiento: mensajes ofensivos reiterados enviados a la persona elegida como blanco por correo 
electrónico, en foros públicos como salas de chat y foros de debate; envío de cientos o miles de mensajes de texto al teléfono móvil de la persona elegida como blanco. Difiere de los insultos porque el hostigamiento es más a largo plazo, es más unilateral (incluyendo a uno o más ofensores frente a una única víctima).

3. Denigración: información despectiva y falsa respecto a otra persona que es colgada en una página web o difundida vía e-mails, mensajes instantáneos..., por ejemplo, fotos de alguien alteradas digitalmente, sobre todo de forma que refleje actitudes sexuales o que puedan perjudicar a la persona en cuestión (foto alterada para que parezca que una adolescente está embarazada, comentarios maliciosos que se escriben en un "cuaderno de opiniones" online en el que se insinúa que una adolescente es sexualmente promiscua)

4. Suplantación: el acosador se hace pasar por la víctima, la mayoría de las veces utilizando la clave de acceso de la víctima para acceder a sus cuentas online y, a continuación, enviando mensajes negativos, agresivos o crueles a otras personas como si hubieran sido enviados por la propia víctima.

5. Desvelamiento y sonsacamiento: Implica revelar información comprometida de la víctima a otras personas, enviada de forma espontánea pero privada por la víctima o que ha sido sonsacada a la víctima y después difundida a otras personas.

6. Exclusión: no dejar participar a la persona de una red social específica.

7. Ciberpersecución: envío de comunicaciones electrónicas reiteradas hostigadoras y amenazantes.

8. Paliza feliz (happy slapping): se realiza una agresión física a una persona a la que se graba en vídeo con el móvil y luego se cuelga en la red para que lo vean miles de personas.

Este fenómeno se ha incrementado en los últimos años, gracias al avance tecnológico que todos estamos expuestos, y más los jóvenes, en tal caso los universitarios y con mucha más precisión las jóvenes universitarias, en nuestro país se han visto y leído casos de jovencitas de 18 a 29 años asesinas, debido a citas que se generan a través de las redes sociales, señoritas que usan 
aplicaciones para solicitar servicios comerciales y son engañadas y secuestradas.

Flores (2008), señala que el Ciberbullying se incrementa por las siguientes razones:

1) Alta disponibilidad de nuevas tecnologías (Internet, móvil)

2) Importancia progresiva del ciberespacio en la vida de las personas como espacio de socialización complementario al contexto del hogar, la escuela o la comunidad.

3) Menor percepción del daño causado que en el bullying, ya que víctima y agresor no están en una situación "cara a cara".

4) Sensación de impunidad del acosador por el anonimato que posibilita y que conlleva que no se enfrente a las represalias de la víctima, de sus compañeros, amigos, padres, responsables escolares, etc.

5) La ausencia de conciencia que tiene el acosador del daño que ejerce, ya que en ocasiones asocia su conducta a un rol, y atribuye la conducta a un personaje o rol interpretado en la Red.
6) Las características propias de Internet que estimula el fácil agrupamiento de hostigadores y la cómoda reproducción y difusión de contenidos audiovisuales. Por lo anterior se presentan los siguientes resultados para sustentar esta investigación.

En este sentido y de igual forma, Bill Belsey presidente de www.bullying.org y www.cyberbullying.ca, contempla los siguientes tipos de cyberacoso: a través del correo electrónico; del teléfono móvil con los mensajes de texto o mensajes multimedia; a través de la mensajería instantánea; weblogs difamatorias; web personales. Según Fante (2005) los jóvenes usan weblogs, redes sociales y sistemas de mensajería instantánea para intimidar a sus compañeros, siendo la difusión de fotografías retocadas para ridiculizar a las víctimas uno de los métodos más empleados. Estas son distribuidas masivamente $\mathrm{y}$ a veces indicando la identidad de aquel que es sometido a la humillación para acrecentar el impacto. En el caso de las comunidades virtuales, muchas de ellas precisan de invitación para poder entrar a formar 
parte de un grupo, el acoso escolar se hombres realizan este acto, como lo basa en aislar a aquellos que son las muestra la

Figura1. víctimas de las humillaciones e intimidaciones.

\section{Resultados}

Dentro de la percepción que tiene los estudiantes del acoso cibernético consideran que tanto mujeres como

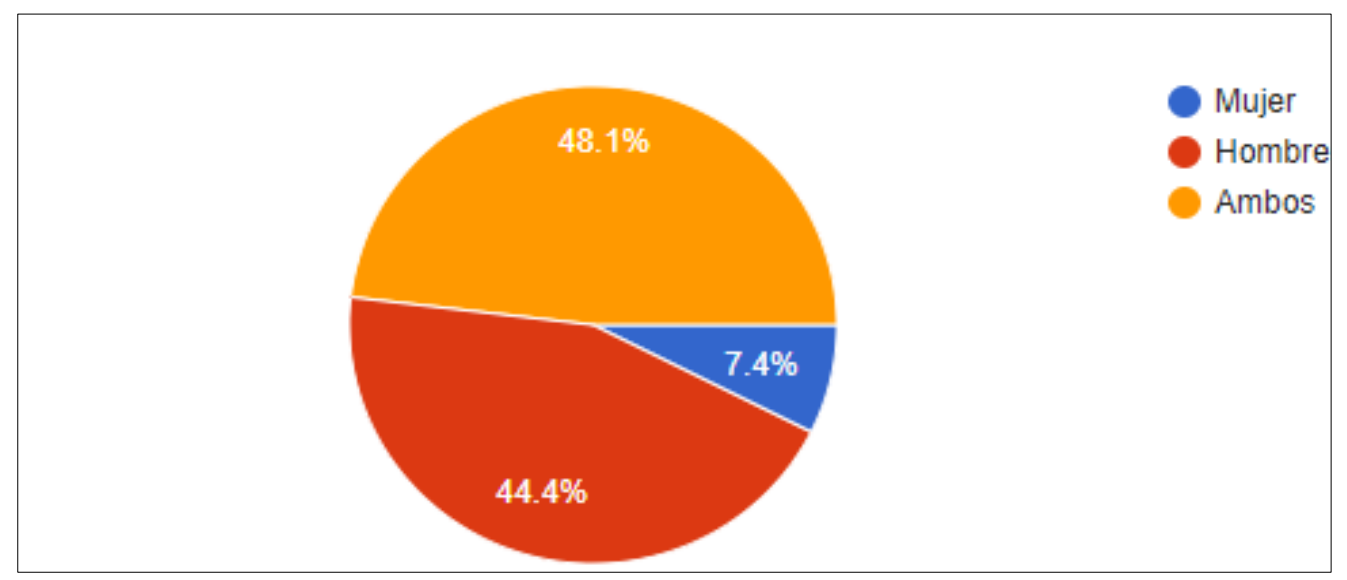

Figura 1. Personas que realizan más acoso.

Como se observa en la Figura 2, el $54.5 \%$ de los estudiantes universitarios encuestados han recibido algún tipo de acoso cibernético lo que demuestra que han sufrido ciberbullying, ya que este es un acoso a través de las TIC, en tanto que el $45.5 \%$ dijo que no ha sufrido ningún tipo de acoso. 


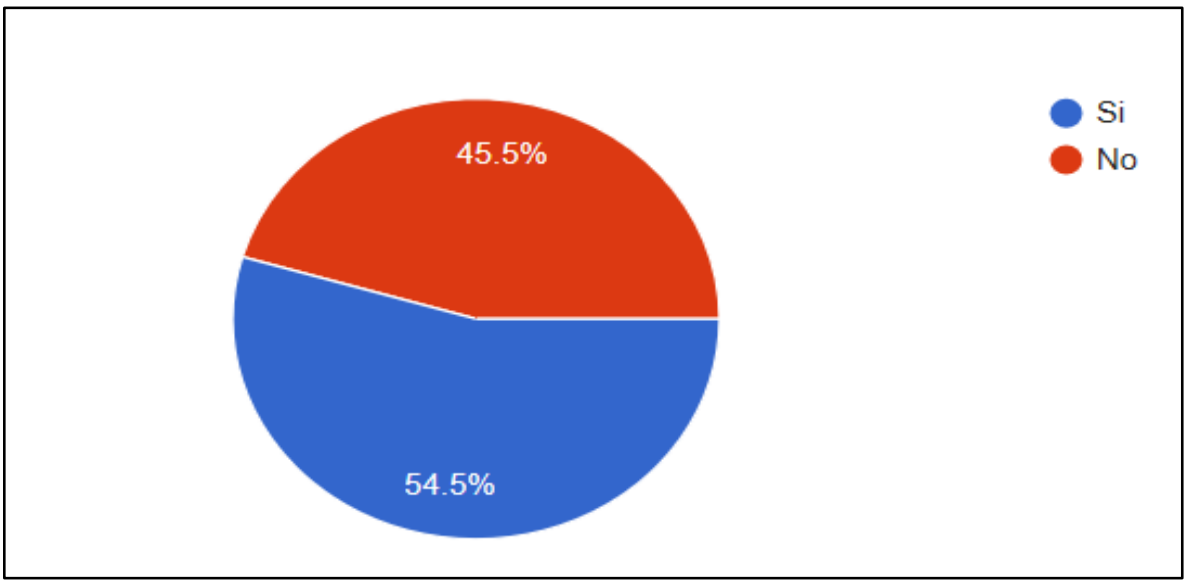

Figura 2. ¿Has recibido algún tipo de acoso?

En la figura 3, se aprecia que los a las personas que se dirigirían en primera instancia en caso de recibir acoso con un $46.4 \%$, serían a los padres ya que son las personas con las que tienen más confianza. Con un $21.4 \%$ los estudiantes universitarios expresaron que, al director de la universidad, con un $10.7 \%$ al profesor $y$ con un $7.1 \%$ con los administrativos.

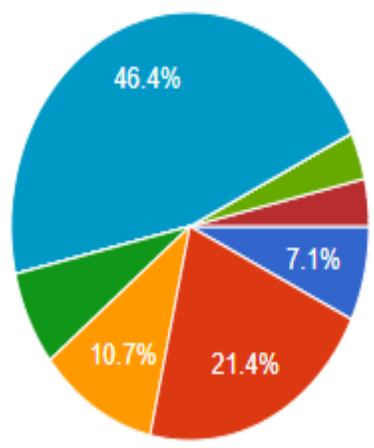

Administrativos

Director

Profesor

Tutor

Sociedad de alumnos

Padres

A ninguna persona

Hermano

Puede que a todos los anterior conocidos

Figura 3. A quien dirigirse en caso de sufrir acoso. 
El medio predominante por la que se ejerce el Ciberbullying o acoso, es el Facebook en un 50\%, seguido por el
WhatsApp con un $35 \%$ y con un $15 \%$ el Chat., así como se muestra en la figura 4.

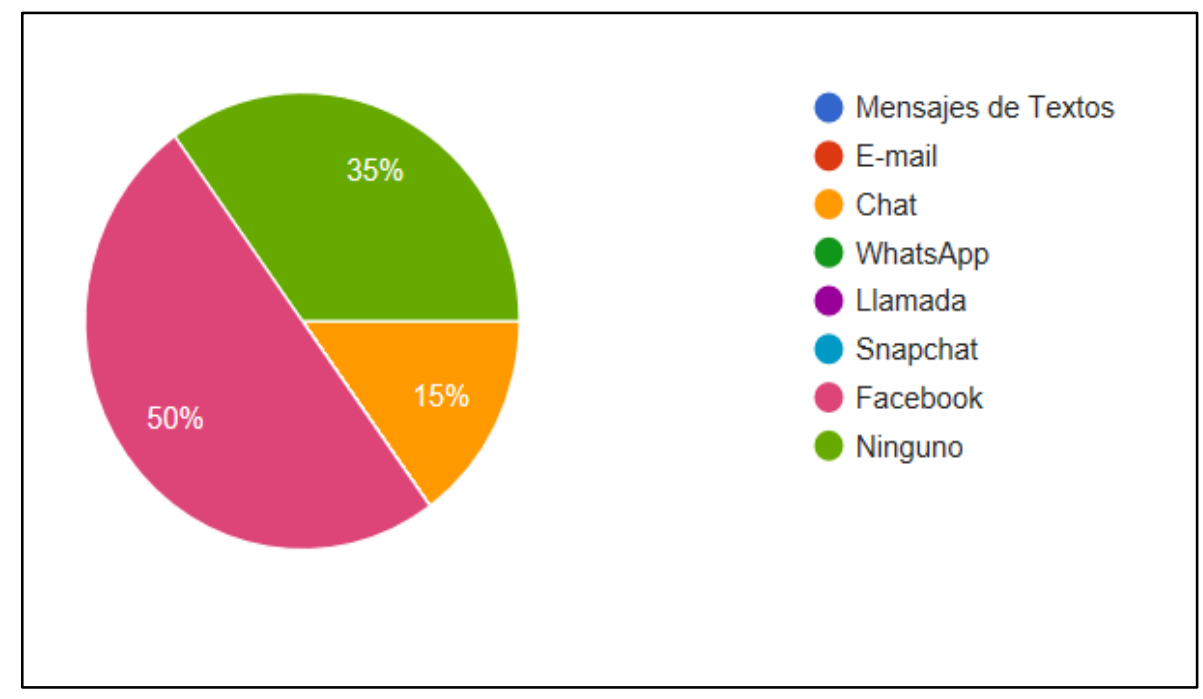

Figura 4. Medios por el cual has recibido acoso.

Debido al acoso o ciberbullying, las reacciones que se presentan en las personas que lo han sufrido son variadas e incluso hasta han llegado a enfermarse, por eso al preguntarle a los estudiantes universitarios que como se han sentido al recibir acoso, un $61.9 \%$ respondió disgustado o enojado, un 19\% no ha recibido $y$ un $9.5 \%$ se sentido decepcionado como se puede observar en la figura 5. 


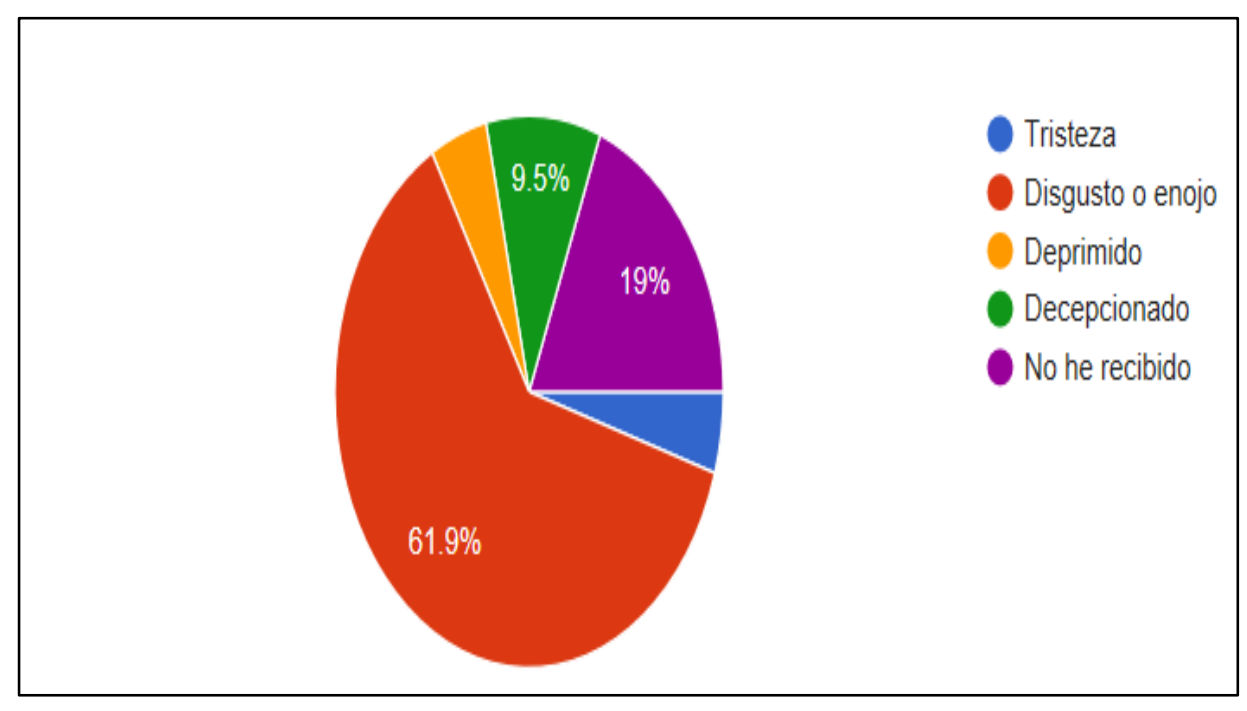

Figura 5. Que has sentido al recibir acoso. 


\section{Conclusión}

Mendoza, E. (2012), menciona que la red social más visitada es Facebook, con más de 800 millones de usuarios, de los cuales 17 millones son niños y jóvenes de 13-19 años. Se suben más de 25 mil millones de contenidos de diferente tipo: videos, fotos, mensajes, historias, etc. Un usuario de Facebook puede tener en promedio 130 amigos, pero al agregar amigos se pueden agregar amigos de amigos, o sea, perfectos desconocidos que podrían esconder a algún depredador (y sabemos que hay niños menores de edad registrados proporcionando una fecha de nacimiento falsa).

Dado los resultados, se confirma en este estudio que por ser la red más usada Facebook es el medio por el cual se realiza más el Ciberbullyng y ha crecido mucho en los últimos años, la mayoría de los estudiantes se sientes enojados por el acoso y el estudiante puede sufrir depresión, baja autoestima, ansiedad social, trastorno de concentración, ideas suicidas, en los resultados de esta encuesta se ve lo increíblemente mal que se puede sentir un estudiante cuando es acosado por lo terrible del Ciberbullyng.

\section{Bibliografía}

Alonso, D. (2016). Manual del BullyingEspaña: Nova Galicia Ediciones.

Álvarez, J. y Jurgenson, G. (2007). Cómo hacer investigación cualitativa. Fundamentos y metodología. México: Paidós.

Enríquez y Garzón (2015). El Acoso Escolar. Saber, Ciencia y Libertad ISSN: 1794-7154 Vol. 10, No.1. Recuperado de: https://dialnet.unirioja.es/descarga/artic ulo/5329121.pdf.

Bell, D. (2006) .Cybercultures an Introduction to Cybercultures. New York: Routledge.

Castro, S. y Reta, B. (2004). Bulling blando, bullying duro y ciberbullying. Nuevas violencias y consumos culturales. Argentina. Homosapiens ediciones.

Corsi, J. y Peyrú G. (Coordinadores) (2003). Violencias sociales. Barcelona: Ariel. 
Fante, C. (2005). Fenómeno Bullying.

Como prevenir a violência nas escolas e educar para a paz. Brasil: Verus.

Flores, J. (2008). Ciberbullying. Guía rápida. Recuperado el 20 de abril 2018 en: http://

www.pantallasamigas.net/proteccioninfancia-consejos-

articulos/ciberbullying-guia-

rapida.shtm.

Franco, G. (2005). Tecnologías de la comunicación: producción, sistemas y difusión digital. Madrid: Fragua.

Instituto Nacional de Tecnologías de la Información, INTECO México (2011). Guía sobre adolescencia y sexting: ¿qué es y cómo prevenirlo Vol. 1, $\mathrm{n}^{\mathrm{o}}$ Recuperado el 20 de abril de 2018 http://www.uoc.edu/rusc/dt/esp/salinas1 104.pdf Jiménez, M. y Farré, M. (2015). Adicción a las nuevas tecnologías. ¿La epidemia del S.XXI? España: Siglantana.

Kowalski, R., Limber, S. y Agatston, P. (2010). Cyber Bullying: El acoso escolar en la era digital. Bilbao: Desclée de Brower.
Mendoza, E. (2012). Acoso cibernético o cyberbullying: Acoso con la tecnología electrónica. Revista Pediatría de México Vol. 14 Núm. 3. Recuperado de:

http://www.medigraphic.com/pediatriad $\underline{\text { emexico }}$

Salinas, J. (2004). "Innovación docente y uso de las TIC en la enseñanza universitaria". Revista de Universidad y Sociedad del Conocimiento (RUSC).

Stopbullying (s/f), sitio web official del Gobierno de Estados Unidos. Disponible en: https://www.stopbullying.gov/ Agencia española de Protección de Datos (2016). Guía para familiares y profesores: Enséñales a ser legales en internet. Disponible en: http://www.tudecideseninternet.es/agpd 1/images/guias/Guia_formadores2016.p $\underline{\mathrm{df}}$

Sandee, L. (2015). Los riesgos del 'cyberbullying' en la universidad. Mujeres universitarias susceptibles al 'cyberbullying' y efectos dañinos. Recuperad0o el 19 de abril del 2018 en: 
Periódico do Núcleo de Estudos e Pesquisas sobre Gênero e Direito

Centro de Ciências Jurídicas - Universidade Federal da Paraíba

V. 9 - No 01 - Ano 2020 - Spanish Edition

ISSN | 2179-7137 | http://periodicos.ufpb.br/ojs2/index.php/ged/index

https://expansion.mx/salud/2015/03/03/

mujeres-universitarias-susceptibles-al-

cyberbullying-y-efectos-

daninos?internal_source=PLAYLIST

Oliva, L. (2013). La violencia escolar

desde la infancia hasta la juventud.

Revista Costarricense de Psicología 